\title{
Naturally Derived Biomaterials: Preparation and Application
}

\author{
Tran Le Bao Ha, To Minh Quan, \\ Doan Nguyen Vu and Do Minh Si \\ Additional information is available at the end of the chapter \\ http://dx.doi.org/10.5772/55668
}

\section{Introduction}

The success of any implant depends so much on the biomaterial used. Naturally derived biomaterials have been demonstrated to show several advantages compared to synthetic biomaterials. These are biocompatibility, biodegradability and remodeling. Therefore, these biomaterials are usually applied in the repair or replacement of damaged human tissues and organs. The aim of this chapter is to provide a brief knowledge of naturally derived biomaterials as well as methods of preparation and application of them.

Biomaterials can be classified into two main groups: synthetic and natural biomaterials. Synthetic biomaterials are classified as: metals, ceramics, nonbiodegradable polymers, biodegradable polymers... Some synthetic biomaterials are commercialized and applied in clinical treatment such as metal hip, Dacron, plastic intraocular lens... However, synthetic biomaterials have some disadvantages, including their structure and composition is not similar to native tissues/organs, their biocompatibility and their ability to induce tissue remodeling are low. Thus, other biomaterials have been developed that can overcome the disadvantages of synthetic biomaterials. Today, naturally derived biomaterials have been attracting scientist's interest all over the world. Naturally derived biomaterial can be classified into many groups including protein-based biomaterials (collagen, gelatin, silk...), polysaccharide-based biomaterials (cellulose, chitin/chitosan, glucose...) and decellularized tissue-derived biomaterials (decellularized heart valves, blood vessels, liver...). Protein and polysaccharide-based biomaterials can be prepared by two distinct ways. Protein and polysaccharide from living organisms are dissolved by solvents or enzymes. Then, they are precipitated and reconstituted into fibrils. The second way to prepare protein and polysaccharide is removing other elements of living organisms by solvents or enzymes. Decellularized biomaterials are created by 
eliminating all cells from native tissues/organs. Physical, chemical and enzymatic approaches are combined to make the effective decellularization protocol.

Because of their advantages, naturally derived biomaterials are usually applied to replace or restore structure and function of damaged tissues/organs. They have ability to adequately support cell adhesion, migration, proliferation and differentiation. In particular, when implanted into a defective area, naturally derived biomaterials can enhance the attachment and migration of cells from the surrounding environment, therefore, induce extracellular matrix formation and promote tissue repair. Some biomaterials are used to acting as drug delivery system and medical devices such as surgical sutures. The silk fiber produced by silkworm or spider has been used as a surgical suture for a long time due to its biodegradable and non-antigenic protein. These silk fibroin nanoparticles are the globules with a fine crystallinity that may offer various possibilities for surface modification and covalent drug attachment. Furthermore, some biomaterials are used to produce environmental friendliness of packaging (such as resorbable chitosan packing) and other products. Some commercial products were made from naturally derived biomaterial such as SIS, Matrigel, Alloderm... In this chapter, we focus on a brief knowledge as well as the methods of preparation and application of naturally derived biomaterials in our researches.

\section{Naturally derived biomaterials: Preparation and application}

\subsection{Protein}

\subsubsection{Collagen}

\subsubsection{Structure}

Collagen is the most abundant protein of connective tissues in all animals. Now, at least sixteen types of collagen have been identified, in which $80-90 \%$ of the collagen is types I, II and III. Collagen is secreted by not only fibroblasts but also epithelial cells [1].

The basic structural unit of collagen is a triple helix. Most collagen is fibrillar because of pack of collagen molecules type I, II, III. Contrast, collagen IV forms a two dimensional network which is unique to the basement membranes [1]. Basement membranes have been performed a number of mechanical and biological functions. They provide physical support for tissue because of their tensile strength. They also influence cell proliferation, adhesion, migration, differentiation, polarization, and are thus implicated in biological processes such as development, tissue maintenance, regeneration, and repair, and in various pathological processes such as tumor growth and metastasis [2].

The basement membranes composition varies from one tissue to another. In general, the major constituents of all basement membranes are collagen IV, laminins, nidogen/entactin, and proteoglycans. The functional diversity of basement membranes arises from the molecular diversity of their components, particularly the different collagen IV and laminin isoforms [2]. 


\subsubsection{Preparation}

Collagen can be obtained from various sources, in which amniotic membrane (AM) is an attractive source. AM is a thin membrane surrounding the fetus which is filled with amniotic fluid.

The AM consists of an epithelial monolayer, a thick basement membrane, a compact layer, a fibroblast layer and a spongy layer [3]. The innermost layer, nearest to the fetus, is monolayer of epithelial cells anchored on the basement membrane. The collagen component of basement membrane of AM includes types III, IV, V, VII, XVII which similar morphological and ultrastructural basement membrane of skin. Therefore, basement membrane of AM is often used to create skin equivalents. Besides, AM has outstanding properties such as anti-inflammatory, anti-bacterial, anti-fibrosis, anti-scaring as well as low immunogenicity and reasonable mechanical features [3].

AM can be used either with amniotic epithelium (intact) or without it (denuded), fresh or preserved. To remove the amniotic epithelium, the AM is incubated in trypsin-EDTA at $37^{\circ} \mathrm{C}$ in $30 \mathrm{~min}$ and the cells are gently scraped while maintaining the intact basement membrane. H\&E staining was performed to confirm removing the amniotic epithelium. Then, the basement membrane can be preserved by drying or glycerol - cryopreservation after $\gamma$ sterilization $[3,4,5]$.

\subsubsection{Application}

Collagen is commonly used in biomedical applications. The basement membrane of the AM is a typical example. The extracellular matrix components of the basement membrane of the $\mathrm{AM}$ are native scaffolds for cell seeding in tissue engineering. AM has been applied in tissue engineering related to eye, skin, cartilage, nerve, especially cancer $[3,6,7]$.
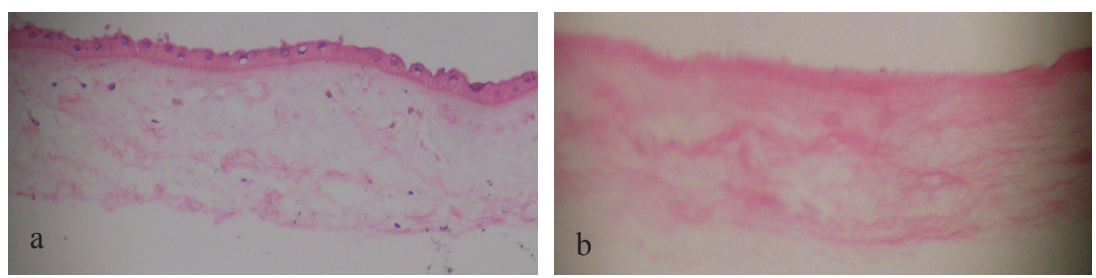

Figure 1. Amniotic membrane with epithelium: intact (a) and denuded (b)

To use AM in creating skin equivalent, AM must be removed the epithelium. Keratinocytes are seeded onto basement membrane which is denuded AM. Briefly, keratinocytes were isolated from intact skin samples by incubation in trypsin-EDTA at $4^{\circ} \mathrm{C}$ in 18 hours and detached mechanically. Keratinocytes were cultured in serum free medium in 7 days. Medium was chanced every two days [8]. After 3rd passage, cells were subcultured onto AM basement membrane which spreaded on bottom of the insert dishes. The cells were maintained in culture for 7 days when the cells reached confluent. Air-lifting was performed to induce cell 
differentiation. After 7 days, the cells formed multi-layers on the AM basement membrane. Cultured keratinocyte sheets were grafted on patients who were defected skin because of injury or burn. The result showed that, the advantages of cultured keratinocyte sheet autograft: the possibility of the grafting area multiplication (50 times after 3 weeks), the diminution of scaring, the relief of pain, the low infection risk, the same effect in compare to the split - thinness autograft.
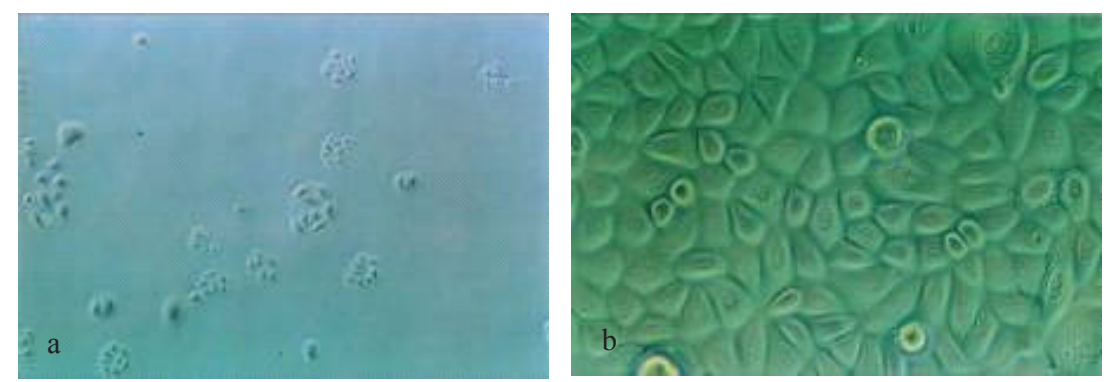

Figure 2. Keratinocytes formed colonies (a) and monolayer onto culture dishes (b) (200X)

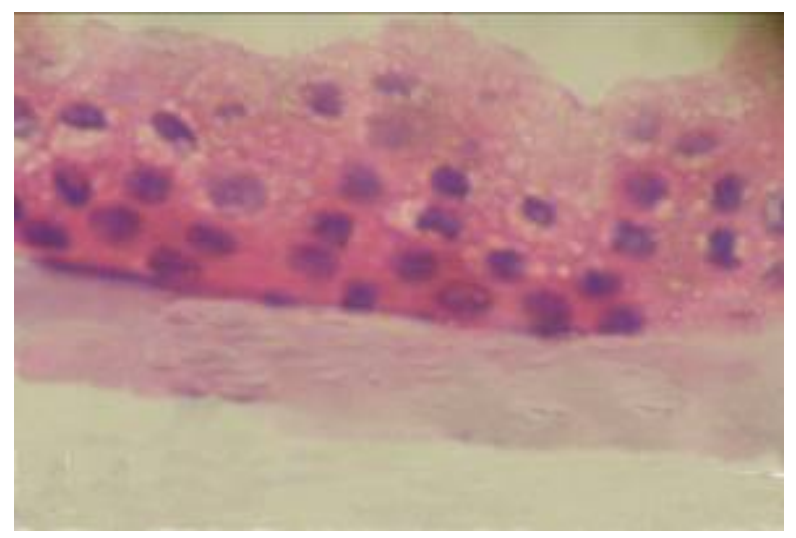

Figure 3. Result of HE staining of the cell sheet, the cells were exposed to the air in seven days. The cells formed $4-5$ layers onto AM basement membrane (400X).

\subsection{Gelatin-Alginate}

\subsubsection{Structure}

Gelatin is obtained by controlling the hydrolysis of collagen, a fibrous insoluble protein which is widely found in nature and is the major component of skin, bone and connective tissue. Characteristic features of gelatin are the high content of the amino acids such as glycine, proline 
and hydroxyproline. Structually, gelatin molecules contain repeating sequences of glycine-X$\mathrm{Y}$ triplets, where $\mathrm{X}$ and $\mathrm{Y}$ are frequently proline and hydroxyproline. These sequences are responsible for the triple helical structure of gelatin and its ability to form gels where helical regions form in the gelatin protein chains immobilizing water [9].

Alginate was first discovered by Edward Stanford in 1883. Since being commercialized in 1927, alginate has now expanded to about 50.000 tonnes per year worldwide; $30 \%$ of this tonnage is devoted to the food industry, the rest being used in industrial, pharmaceutical and dental applications [10]. The function of alginates in algae is primarily skeletal, with the gel located in the cell wall and intercellular matrix conferring the strength and flexibility necessary to withstand the force of water in which the seaweed grows [11].

Alginate is a hydrophilic polysaccharide extracted from marine brown algae such as Laminaria hyperborea or soil bacteria such as Azobacter vinelandii and composed of 1,4-linked $\beta$-Dmannuronic acid $(\mathrm{M})$ residues and 1,4-linked $\alpha$-L-guluronic acid $(\mathrm{G})$ in varying proportions, displaying carboxylic acid functionality at the $\mathrm{C} 5$ residue. The alginates have broad distributions of molecular weights of 10-1000 kDa depending on source and processing. The relative amount and sequential distribution of homogeneous M-M segments (M-blocks), homogeneous G-G segments (G-blocks) and alternating M-G segments (MG-blocks), which represent the primary structure of alginate, depend on the producing species, and for marine sources, on seasonal and geographical variations.

\subsubsection{Preparation}

Cross-linked gelatin/alginate was made in two steps. Briefly, $1 \mathrm{wt} \%(\mathrm{w} / \mathrm{w})$ aqueous solution of gelatin and sodium alginate, respectively, was dissolved in double distilled water at 500C for $3 \mathrm{~h}$. Each solution with certain mixing ratios of gelatin and sodium alginate (8G:2A) was stirred for $30 \mathrm{~min}$ at room temperature, frozen to $-700 \mathrm{C}$ for $40 \mathrm{~h}$. This soluble sponge was crosslinked with EDC by immersing the soluble sponge in $90 \%(\mathrm{w} / \mathrm{v})$ aqueous acetone containing $0.3 \%$ EDC for $24 \mathrm{~h}$ at room temperature, while shaking slowly.
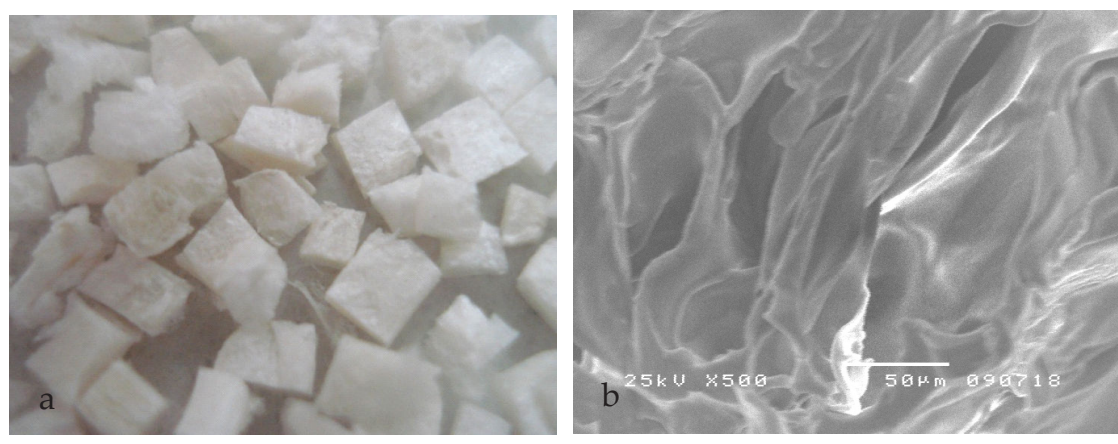

Figure 4. Gelatin-Alginate. Block (a), SEM (b) 
The sponges consisting of gelatin from hydrolysis of collagen and alginate-a polysaccharide from Phaeophyta were established by using EDC as a crosslinking agent. The sponges were combined with some natural substances traditional used for burn treatment such as tamanu oil (from nuts of Calophyllum inophyllum); cajeputi oil (from leaves of Meulaleuca leucadendron); madecassol (from extract of Centella asiatica); turmeric and python fat. Data obtained from testing on mice showed that the coordinated sponges have rather good ability on preventing infection and promoting wound healing compared with control. The sponges combined with mixture of cajeputi oil and madecassol have the best potential for burn treatment.

\subsubsection{Application}

Gelatin has been used in medicine as plasma expander, wound dressing, adhesive, and absorbent pad for surgical use. While collagen, also known to have wide biomedical applications, expresses antigenicity in physiological condition, gelatin is known to have no such antigenicity. Recently, gelatin has shown to exhibit activation of macrophages and high hemostatic effect. Finally, gelatin is practically more convenient than collagen because a concentrated collagen solution is extremely difficult to prepare from the native collagen, and furthermore gelatin is far more economical than the collagen.

Alginate is an effective natural disintegrant, tablet binder and offers an attractive alternative for sustained-release systems. It offers advantages over synthetic polymers as it forms hydrogels under relatively mild $\mathrm{pH}$ and temperature and is generally regarded as non-toxic, biocompatible, biodegradable, less expensive and abundantly available in nature; in addition, alginate meets the important requirement of being amenable to sterilization and storage. All these advantages make alginates very useful materials for biomedical applications, especially for controlled delivery of drugs and other biologically active compounds and for the encapsulation of cells. Calcium alginate is a natural haemostat, so alginate based dressings are indicated for bleeding wounds. The gel forming property of alginate helps in removing the dressing without much trauma [12].

Alginate has been much used in medical applications such as wound dressings, scaffolds for hepatocyte culture and surgical or dental impression materials. Alginates are also known to be broken down to simpler glucose type residues and can be totally absorbed.

Alginate has been successfully used as a matrix for the entrapment and/or delivery of biological agents, such as drugs and proteins. In particular proteins can be loaded and released by alginate matrices without loss of their biological activity because of the relatively mild gelation process of alginate. In pharmaceutical formulations, the alginate gel can be prepared prior to use, or it can spontaneously form in situ in physiological fluids, by low $\mathrm{pH}$ and/or calcium ions naturally present in the site of administration [13]. Alternatively, the gelling agent can be added either as a part of the formulation or separately administered. The microencapsulation technique has been specifically developed for the oral delivery of proteins, as they are quickly denaturated and degraded in the hostile environment of the stomach.

Among the possible applications of alginate, one of the most promising is for cell immobilization. Alginate gel allows cell suspension to be cultivated in several types of bioreac- 
tors to achieve high cell densities [14]. In cell immobilization applications, the main drawback of alginate matrix gels is represented by their high density of network, which limits the cell growth; moreover, cell anchorage, a strict requirement for survival, is limited on alginate gels, because of its hydrophilic nature. PEG copolymers are used to improve their biocompatibility [15].

\subsection{Silk}

Silks are generally defined as protein polymers that are spun into fibers by Lepidoptera larvae such as silkworms, spiders, scorpions, mites and flies [16]. Silks are fibrous proteins synthesized in specialized epithelial cells that line glands in these organisms. Silk fibroin polymers consist of repetitive protein sequences and provide structural roles in cocoon formation, nest building, traps, web formation, safety lines and egg protection. The most extensively used silk for various applications are those from silkworm silk; Bombyx mori and spider silk; Nephila clavipes.

The domesticated silkworm (B. mori) silk fibroin fibers are about 10-25 $\mu \mathrm{m}$ in diameter. Each fiber consists of core protein covered by a coating protein (sericin) that glues core fibers together. The core protein consists of three chains: heavy chain, light chain and a glycoprotein, P25. The light chain $(26 \mathrm{kDa})$ and heavy chain $(390 \mathrm{kDa})$ which are present in a 1:1 ratio and linked by a single disulfide bond. The disulfide linkage between the Cys-c20 (20th residue from the carboxyl terminus) of the heavy chain and Cys-172 of the light chain holds the fibroin together and a $25 \mathrm{kDa}$ glycoprotein, named P25, is non-covalently linked to these proteins [17]. Light chain is necessary for the secretion of protein from the silk glands. Heavy chain is fiber forming protein and its structure determines properties of silk fiber [18]. Heavy chain is commonly referred as fibroin protein. These proteins are coated with a family of hydrophilic proteins called sericins $(20-310 \mathrm{kDa})$. Silk proteins are particularly promising for these needs due to their unique combination of biocompatibility, biodegradability, self-assembly, mechanical stability, controllable structure and morphology.

Spiders are look like insects and come in to the category of Arthropoda, but they belong to a completely different class of animals, called Arachnida. Spider silk is the result of 400 million years of evolution. Spiders use silk for variety of functions including reproduction as cocoon capsular structures, lines for prey capture, lifeline support (dragline), web construction and adhesion. Spider silk is a biopolymer fiber. Its composition is a mix of an amorphous polymer (which makes the fiber elastic), and chains of two of the simplest proteins (which give it toughness). Out of 20 amino acids, only Glycine and Alanine serve as a primary constituent of silk. The Dragline silk of orbweb spider seems to be most studied in the scientific research. The protein in dragline silk is fibroin (Mass of 200,000-300,000 Daltons) which is a combination of the proteins spidroin 1 (Alanine-rich) and spidroin 2 (Glycine-rich), the exact composition of these proteins depends on species. Fibroin consists of approximately $40 \%$ Glycine and $25 \%$ Alanine as the major amino acids. The remaining components are mostly glutamine, serine, leucine, valine, proline, tyrosine and arginine [19]. Nephila clavipes can produce seven types of silk from seven different silk glands as shown in depending on needs and environmental 
conditions [20]. The superior mechanical properties of dragline spider silks can be used as a template for developing specific structures for various biomaterial needs. Spider silks have not been commercialized in fashion as silkworm silk due to the lack of domestication and lower productivity of spiders.

\subsubsection{Preparation}

Nanotechnology is becoming a key technology and capable of application in all fields of science and technology. In particular, nanoparticle delivery system significantly improved pharmaceutical treatment of many incurable diseases which require complex treatment regimens, as well as, patients must take multiple medications and need time long-term drug use. Silk Protein is the ideal material for this purpose, because they have many unique features such as highly biocompatible and biodegradable ability, self-restructuring, mechanical stability, easy control and adjustment of the object's structure and shape.


Figure 5. Nanofibroin particles

The cocoon shell of silkworm Bombyx mori was degummed in boiling solution of $0,5 \%$ $\mathrm{Na} 2 \mathrm{CO} 3$ in $700 \mathrm{C}$ for $35 \mathrm{~min}$. Then degummed fiber was dissolved in a mixed solution of calcium chloride, ethanol, and water $(\mathrm{CaCl} 2 / \mathrm{C} 2 \mathrm{H} 5 \mathrm{OH} / \mathrm{H} 2 \mathrm{O}: 1: 2: 8$ mole ratio), at $800 \mathrm{C}$. After the silk fibroin-salts solution was centrifuged at $5000 \mathrm{rpm}$ for $10 \mathrm{~min}$, the supernatant was dialyzed continuously for $72 \mathrm{~h}$ against running pure water to remove $\mathrm{CaCl} 2$, smaller molecules, and some impurities. The resulting liquid silk fibroin was stored at $40 \mathrm{C}$ and used in the following experiments for the preparation of silk fibroin nanoparticles. Spider silk proteins form nanoparticles upon salting out with potassium phosphate. Milk-like silk protein particles 
were formed at once and suspended in the mixture comprising water and organic solvent. These protein particles were water insoluble and went down slowly due to the gathering of microparticles. The precipitates of silk protein nanoparticles were collected and purified from the mixture by repeated centrifugation at 20,000 rpm to separate these particles from the solvent. After the research, we have obtained nanoparticles (500 nm-2000 nm) from silk protein can load and delivery of proteins in vitro.

\subsubsection{Application}

The silk bio-polymer is used in tissue regeneration for treating burn victims and as matrix of wound healing. The silk fibroin peptides are used in cosmetics due to their glossy, flexible, elastic coating power, easy spreading and adhesion characters [21]. Silk powder is touted and relieves from sunburns, due to crystalline structure it reflects UV radiation and as demulcent it acts as protective buffer between skin and environment. The lower micron silk powder is added with hair and massage oils and water dispersible finer grade silk powder is an ingredient of liquid cosmetic preparations.

The silk is used to fight edema, cystitis, impotence, adenosine augmentation therapy, epididymitis and cancer [22]. Silk protein derivative, Serratio peptidase is used as anti-inflammatory, anti-tumefacient for treating acute sinusitis, tonsiloctomy, oral surgery, tooth filling, cleaning and extractions. The silk fibroin is a useful dressing material with the property of noncytotoxic to the tissues and also in veterinary medication.

Since long, silk fiber is being used as surgical sutures as it does not cause inflammatory reactions and is absorbed after wounds heal. Other promising medical applications are as biodegradable micro tubes for repair of blood vessels and as molded inserts for bone, cartilage and teeth reconstruction [23, 24, 25]. In biomedical and bioengineered field, the use of natural fibre mixed with biodegradable and bio-resorbable polymers can produce joints and bone fixtures to alleviate pain for patients.

Drug delivery is a rapidly developing field in biomedical research. It is interdisciplinary and requires expertise in biotechnology, pharmacology, microbiology, biochemistry, polymer chemistry and materials engineering. Advantages of using such systems include maintenance of drug levels within desired range, fewer administrations, optimal use of the drug, and better patient compliance. The material used for drug delivery should be biocompatible, chemically inert, easily processable and physically and mechanically stable. Biopolymers are of great interest for this kind of application. Silk and silk-like variants are used by some scientists as carriers for drug delivery. Their biocompatibility and ability to form hydrogels in situ makes them attractive candidates for the localized, controlled delivery of therapeutic agents. Their ability to incorporate drugs at room temperature, by simple mixing, and without the use of toxic or denaturing solvents makes them attractive for the delivery of protein or DNA-based therapies [26].

Future applications of silk biomaterials include new generation soft contact lenses that enable greater oxygen permeability, artificial corneas, skin grafts and epilepsy drug permeable devices. 


\subsection{Fibrin}

\subsubsection{Structure}

The mechanism of fibrin fomation is elucidated primarily from the thrombin-mediated cleavage of fibrinogen. Fibrinogen, the principal protein of blood clotting, is a $340 \mathrm{kDa}$ trinolar protein which presents at high concentration in blood plasma $(2-4 \mathrm{mg} / \mathrm{ml}, 6-12 \mu \mathrm{M})$. Fibrinogen molecule consists of three different pairs of polypeptide chains ( $\mathrm{A} \alpha, \mathrm{B} \beta$ and $\gamma$ ) cross-linked to each other by 29 disulfide bridges (Fig. 1). The amine-termini (N-termini) of six polypeptide chains are converged in the central of fibrinogen molecule called the E domain. The carboxy-termini (C-termini) of the $\mathrm{B} \beta$ chain and $\gamma$ chain comprise of the distal $\mathrm{D}$ domain. The C-termini of A $\alpha$ chains which are known as globular, depart from the $\mathrm{D}$ domain and fold into a conformation that stretches back toward the E domain of fibrinogen [27].

Fibrinogen plays as precursor protein of fibrin in blood clotting. The conversion of fibrinogen to fibrin occurs in 3 ordered steps. In the intinial step, thrombin binds to the central E domain of fibrinogen and slipts off the fibrinopeptides A - FpA (16 amino acid residues) and B - FpB (14 amino acid residues) from $\mathrm{N}$-termini of $\mathrm{A} \alpha$ and $\mathrm{B} \beta$ chains, respectively, whereas the $\gamma$ chains remain unaltered. The cleavage of FpA and FpB results in exposure of " $A$ " and " $B$ " binding sites. Then, the self-assembly proccess will spontaneously occur. The " $A$ " and " $B$ " sites will interact with complementary sites (" $a$ " and " $b$ " sites located in the $\gamma$ and $\beta$ chain) at the $\mathrm{D}$ domain of other fibrinogen molecules, which results in new fibrin monomers. The fibrin monomers are bound to each other non-covalently (Fig. 2) and assemble in a half-staggered manner into two-stranded protofibrils which continue to aggregate laterally to form fibers branching into a three-dimensional network of fibrin [28, 29]. Finally, fibrin cross-linking is activated by Factor XIII (FXIII) in order to improve the strong and elastic properties, additionally, avoid fibrinolysis in solution [30, 31].

\subsubsection{Fabrication of fibrin gel}

According to the usage purposes, some methods have been applied to fabricate fibrin gels. Fibrin gels can be conducted either from the separating components including thrombin, fibrinogen and $\mathrm{CaCl} 2$, or from serum of patients, which will be mentioned in two following methods, respectively. For manipulation of fibrin gel from separating commercial components, fibrin gels were prepared by combining fibrinogen, $\mathrm{NaCl}$, thrombin, $\mathrm{CaCl}$. This complex is also supplemented with aprotinin in order to proving a stable fibrin structure and prevents postoperative bleeding. The contents are allowed to gel for $1 \mathrm{hr}$ in standard culture conditions [32]. Furthermore, fibrin gel physical properties can be manipulated by adjusting the fibrinogen and $\mathrm{CaCl}_{2}$ concentration [33,34], or using different cross linking agents such as enzymes or UV radiation [35]. In terms of autologous fibrin glue, the patient blood is havested and prepared 3 to 4 days before surgery. The plasma is separated from red blood cells by allowing the blood tube to stand vertically for at least 2 hours or centrifuged at $4000 \mathrm{rmp}$ for 5 minutes. The fibrin gel preparation is created by combining plasma with commercial thrombin and calcium at appropriate concentration [36]. Autologous plasma fibrin gel not only 
shows an excellent hemostatic agent, but also helps eliminate the risk of viral transmission associated using donor plasma.

\subsubsection{Fibrin gel applications}

Numerous studies have exploited fibrin function as heamostatic plug, scaffold for cell proliferation and migration, and wound healing, which suggest fibrin potential applications in medical and tissue engineering. Fibrin glue or fibrin sealant is a formulation of fibrinogen and thrombin at very high amounts cobined with calcium and FXIII, used as an adjunct to hemostasis in patients undergoing surgery. Commercial products of fibrin sealant such as Tisseel (Immuno, Vienna, Austria), Beriplast (Behringwerke AG, Marburg/Lahn, FRG), and Biocol (CRTS, Lille, France) have been extensively used in clinical. In addition to fibrin'role in heamostatic, fibrin is also indicated as biological scaffold for cell proliferation, migration and differentiation applied in various tissue engineering. Natural fibrin matrix consists of sites for cellular binding, and has been shown to have excellent effects in cell culture and accelabrate tissue regeneration. In 2000, Ye et al. fabricated and investigated the three-dimensional fibrin scaffold in cardiovascular tissue engineering. In this research, human myofibroblasts (MFBs) from the ascending aorta were cultured in fibrin gel solution. Consequently, the cell growth, high collagen secretation and tissue development were determined. Besides, toxic degradation or inflammatory reactions was not detected in the fibrin gels [37]. In 2003, W. Bensa.1d and colleagues conducted a research in which they use fibrin glue as a delivery system for human MSCs (HMSCs). The result confirmed a good good HMSCs spreading and proliferation in the fibrin scaffold. Besides, the HMSCs migration out of the fibrin scaffold and appearance of calcium carbonate from the differentiation of HMSCs when implanted in vivo suggest that fibrin gel is a promising delivery system for HMSCs toward bone healing application [38]. Fibrin glue also performs its role in the application of skin grafts to burned areas. Using fibrin glue instead of sutures or pressure dressings in the immediate postoperative period enhances healing, and minimizes scarring [39]. One of commercial fibrin sealant products used for burn treatment is ARTISS fibrin sealant (Baxter International Inc., USA). ARTISS fibrin sealant is indicated to adhere autologous skin grafts to surgically prepared wound beds resulting from burns, for both adults and pedipatients.

\section{Polysaccharide}

\subsection{Cellulose}

\subsubsection{Structure}

Cellulose is the most abundant polymer on Earth, which makes it also the most common organic compound. Annual cellulose synthesis by plants is close to $10^{12}$ tons. Plants contain approximately $33 \%$ cellulose whereas wood contains around $50 \%$ and cotton contains $90 \%$. Most of the cellulose is utilised as a raw material in paper production. This equates to approximately $10^{8}$ tons of pulp produced annually. From this, only 4 million tons are used for further 
chemical processing annually. It is quite clear from these values that only a very small fraction of cellulose is used for the production of commodity materials and chemicals [40]. Cellulose, a linear polysaccharide of up to $15,000 \mathrm{D}$-glucose residues linked by $\beta$-(1 $\rightarrow 4)$-glycosidic bonds, is biocompatible and has excellent thermal, mechanical properties. It is considered easily biodegradable, thus less contaminating to the environment.

Cellulose is regarded as a semi-flexible polymer. The relative stiffness and rigidity of the cellulose molecule is mainly due to the intramolecular hydrogen bonding. This property is reflected in its high viscosity in solution, a high tendency to crystallise, and its ability to form fibrillar strands. The chain stiffness property is further favoured by the $\beta$-glucosidic linkage that bestows the linear form of the chain. The chair conformation of the pyranose ring also contributes to chain stiffness. This is in contrast to the $\alpha$-glucosidic bonds of starch [41].

Plants are an attractive cellulose source primarily because they are abundant and there is a preexisting infrastructure in the textile industries for harvesting, retting/pulping (i.e. to treat and isolate micron sized cellulose particles), and product processing. Tunicates are the only animals known to produce cellulose microfibrils. Tunicates are a family of sea animals that have a mantle consisting of cellulose microfibrils embedded in a protein matrix. It is this thick leathery mantle in their mature phase that is used as a source of cellulose microfibrils. Most research has used a class of Tunicates that are commonly known as "sea squirts" (Ascidiacea), marine invertebrate filter feeders. Several algae species such as green, gray, red, yellowgreen... produce cellulose microfibrils in the cell wall. There are considerable differences in cellulose microfibril structure between the various algae species caused by differences in the biosynthesis process. Most cellulose microfibril researchers have used various species of green algae. Bacterial cellulose (BC) is a glucose polymer produced through bacterial fermentation. This macromolecular polymer features the same molecular formula and properties of natural cellulose. A fiber bundle of 40 to $60 \mathrm{~nm}$ thick is formed by micro-fibers with a diameter range of 3 to $4 \mathrm{~nm}$. These bundles aggregate randomly to produce a developed structure forming a typical type of nanobiomaterial [42].

Cellulose derivatives and composites offer an excellent biocompatibility, and are considered as promising materials for biochemical engineering for economic and scientific reasons.

- Oxidized cellulose (oxycellulose) is cellulose in which some of the terminal primary alcohol groups of the glucose residues have been converted to carboxyl groups. Therefore, the product is possibly a synthetic polyanhydrocellobiuronide and that contain $25 \%$ carboxyl groups are too brittle and too readily soluble to be of use. Those products that have lower carboxyl contents are the most desirable[43].

- Purified microcrystalline cellulose (MCC) is partially depolymerized cellulose prepared by treating $\alpha$-cellulose, obtained as a pulp from fibrous plant material, with mineral acids. Silicified MCC (SMCC) is manufactured by codrying a suspension of MCC particles and colloidal silicon dioxide such that the dried finished product contains $2 \%$ colloidal silicon dioxide. SMCC shows higher bulk density than the common types of MCC. Also, tensile strength of compacts of SMCC is greater than that of the respective MCC and it is most probably a consequence of intersurface interactions of silicon dioxide and MCC [44]. 
- The esterification can be considered as a typical equilibrium reaction in which an alcohol and acid react to form ester and water. Cellulose is esterified with certain acids such as acetic acid, nitric acid, sulfuric acid, and phosphoric acid. A prerequisite is that the acid used can bring about a strong swelling thus penetrating throughout the cellulose structure. Cellulose acetate phthalate is a partial acetate ester of cellulose that has been reacted with phthalic anhydride. One carboxyl of the phthalic acid is esterified with the cellulose acetate. The finished product contains about $20 \%$ acetyl groups and about $35 \%$ phthalyl groups [45].

\subsubsection{Preparation}

The treatments for wood and plants involve the complete or partial removal of matrix materials (hemicellulose, lignin, etc.) and the isolation of individual complete fibers. Fortunicate the treatment involves the isolation of the mantel from the animal and the isolation of individual cellulose fibrils with the removal of the protein matrix. Treatments for algal cellulose sources typically involve culturing methods, and then purifying steps for removal of algal wall matrix material. Bacterial cellulose treatments focus on culturing methods for cellulose microfibrillar growth and then washing to remove the bacteria and other media.

The general processing of engineered BC materials can be considered to occur in four main stages: (1) BC culturing, (2) pellicle management, (3) water removal, and (4) chemical modification. For stage 1, the biosynthesis of BC occurs in culture solutions, generally in a bioreactor, in which bacteria secrete cellulose microfibrils, producing an interwoven web of fibrils that is a hydrogel. The hydrogels are composed of entangled cellulose microfibrils formed from the random motion of the bacteria, contain upwards of $99 \%$ water, and are called pellicles. For stage 2, pellicle management refers to any process imparted on the pellicle up until the point of water removal. To remove the bacteria from the pellicles, the pellicles are washed by boiling in a low concentration $(2 \%) \mathrm{NaOH}$ bath for several hours, then it is rinsed under running water for several days. Additional $\mathrm{NaOH}$ and $\mathrm{NaClO}$ treatments have also been used for further purification of the BC microfibrils. For stage 3, once the pellicle is formed and purified, a sample is cut from the gel-like sheet. Water removal either by evaporation or a combination of pressing and evaporation collapses the gel-network and produces a dense film. For stage 4, chemical modification to the BC microfibril network can be achieved at three points along the engineered $\mathrm{BC}$ material processing, (i) during stage 1, (ii) during stage 2, and (iii) after stage 3 (i.e. to dried BC structures or films) [42].

\subsubsection{Application}

Cellulose is extensively used as a raw material in the paper industry in the production of paper and cardboard products. However, cellulose has shown its versatility in numerous applications.

Natural cellulose spheres are often applied in bioseparation, immobilized reaction, cell suspension culture, and as an adsorbent for sewage treatment. Spherical BC produced from dynamic method is translucent, loose, porous, and has a hydrophilic network structure. Its specific surface area increases with decreasing spherical diameter, so it could be used as a 
carrier to adsorb or crosslink various kinds of substances (e.g., enzyme, cell, protein, nucleic acid, and other compounds). Spherical BC may be applied in bioseparation, immobilized reaction, cell suspension culture, and as an adsorbent for sewage treatment. Compared with natural spherical cellulose, the fermentation production of $\mathrm{BC}$ spheres is simple, controllable and environment friendly. Moreover, BC sphere can be used repeatedly, expanding their potential applications.

Cellulosic derivatives such as cellulose acetate, cellulose propionate and cellulose acetatebutyrate, cast as membranes, have been reported as useful supports for immobilizing various enzymes such as catalase, alcohol oxidase and glucose oxidase. These supports gave better activity and storage stability for the enzymes. Cellulose ethers are widely used as important excipients for designing matrix tablets. On contact with water, the cellulose ethers start to swell and the hydrogel layer starts to grow around the dry core of the tablet. The hydrogel presents a diffusional barrier for water molecules penetrating into the polymer matrix and the drug molecules being released. Cellulose acetate butyrate microcapsules, as well as cellulose-based microspheres, have been used for the delivery of drugs [46].

Microbial cellulose synthesized by Acetobacter xylinum shows considerable potential as a novel wound healing system, resulting from its unique nanostructure. During the process of biosynthesis, various carbon compounds of the nutrition medium are utilized by the bacteria, then polymerized into single, linear $\beta$-1,4-glucan chains and finally secreted outside the cells through a linear row of pores located on their outer membrane. Cellulose derived from Acetobacter xylinum, as discussed above in the context of wound healing, has also been explored as a potential scaffold material, due to its unusual material properties and degradability. Moreover, bacterial cellulose derived from Acetobacter xylinum has an ultrafine network architecture, high hydrophilicity, and mouldability during formation. In addition to the applications discussed, it is also suitable for use in micronerve surgery and as an artificial blood vessel suitable for microsurgery [47].

\subsection{Chitin-Chitosan}

\subsubsection{Structure}

Chitin is a white, hard, inelastic, nitrogenous polysaccharide found in the exoskeleton as well as in the internal structure of invertebrates. Chitin is a hydrophobic linear polysaccharide derived from many natural sources including the exoskeleton of arthropods and insects and is the second most abundant natural polysaccharide next to cellulose. Chitin comprises a polysaccharide consisting of $(1 \rightarrow 4)-\beta$-N-acetyl-D-glucosamine units. Derivatives of chitin may be classified into two categories; in each case, the $\mathrm{N}$-acetyl groups are removed, and the exposed amino function then reacts either with acyl chlorides or anhydrides to give the group NHCOR or is modified by reductive amination to $\mathrm{NHCH}_{2} \mathrm{COOH}$ of greatest potential importance are derivatives of both types formed by reaction with bi or polyfunctional reagents, thus carrying sites for further chemical reaction [48]. In practice, such reactions are carried out on native chitin or on incompletely deacetylated chitin, chitosan, so that the resulting polymer contains three types of monomeric units. 
Chitosan is a partially deacetylated derivative of chitin and is the second most abundant biosynthesized material. Structurally, chitosan is a mixture of N-acetyl-D-glucosamine and Dglucosamine [49]. Generally, chitosan is insoluble in neutral or basic conditions, while protonation of free amino groups facilitates solubility of chitosan in dilute acids $(\mathrm{pH}<6)$. In vivo degradation of chitosan is mainly attributed to the effect of lysozyme through hydrolysis of acetylated residues.

Chitosan itself chelates metal ions, especially those of transition metals, and also finds application as a matrix for immobilization of enzymes. Special attention has been given to the chemical modification of chitin, since it has the greatest potential to be fully exploited. Reactions with pure chitin have been carried out mostly in the solid state owing to the lack of solubility in ordinary solvents. A $50 \%$ deacetylated chitin has been found to be soluble in water [50]. This water soluble form of chitin is a useful starting material for its smooth modifications, through various reactions in solution phase. Some of the very recently reported chitosan derivatives are enumerated as follows:

- Fully deacetylated chitosan was treated with phthalic anhydride to give N-phthaloylchitosan. It was readily soluble in polar organic solvents. Further reactions had been carried out using this new derivative to improve the solubility of chitosan [51].

- To improve water solubility, Sashiwa et al. has successfully synthesized dendronized chitosan-sialic acid hybrids by using gallic acid as focal point and tri(ethylene glycol) as spacer arm. The water solubility of these novel derivatives was further improved by Nsuccinylation of the remaining amine functionality [52].

- Recently, Baba et al. have synthesized methylthiocarbamoyl and phenylthiocarbamoyl chitosan derivatives to examine the selectivity toward metal ions from aqueous ammonium nitrate solution [53].

- The synthesis of chitosan hydrogels was carried out by Qu et al. by direct grafting of D,Llactic and/or glycolic acid onto chitosan in the absence of catalysts. They demonstrated that a stronger interaction existed between water and chitosan chains after grafting lactic and/or glycolic acid. The side chains could aggregate and form physical crosslinking, which results in $\mathrm{pH}$ sensitive chitosan hydrogels [54].

\subsubsection{Preparation}

Chitin is easily obtained from crab or shrimp shells and fungal. In the first case, chitin production is associated with food industries such as shrimp canning. In the second case, the production of chitosan-glucan complexes is associated with fermentation processes, similar to those for the production of citric acid from Aspergillus niger, Mucor rouxii, and Streptomyces, which involves alkali treatment yielding chitosan-glucan complexes. The alkali removes the protein and deacetylates chitin simultaneously. Depending on the alkali concentration, some soluble glycans are removed. The processing of crustacean shells mainly involves the removal of proteins and the dissolution of calcium carbonate which is present in crab shells in high concentrations. The resulting chitin is deacetylated in $40 \%$ sodium hydroxide at $120^{\circ} \mathrm{C}$ for 1-3 $\mathrm{h}$. This treatment produces $70 \%$ deacetylated chitosan [55]. 


\subsubsection{Application}

Chitin and chitosan are known for their excellent biological properties, among which the biocompatibility with human cells, the ordered regeneration of wounded tissues, the immunoenhancing activity, the induction of immediate hemostasis, the radical scavenging activity, and the antimicrobial activity. Recent studies indicate that chitin and chitosan are most versatile in drug and gene delivery, elaborated diagnostics, devices for selective recognition of tumor cells, and surgical aids ranging from anti-adhesion gels to coated sterile stents.

As a kind of renewable resource, unmodified chitosan has been widely used in many fields such as pharmaceutical, agriculture, food, and biomedical applications. In order to realize the full potential of chitosan and bring a breakthrough in its broader utilization, attempts have been made to modify chitosan to obtain various derivatives. For the tissue repair and regeneration applications, chitosan can be functionalized by chemical reaction, coupling with specific ligands or moieties, combining with biomacromolecules, and crosslinking in the presence or absence of crosslinkers.

Particularly, skin substitute made of chitosan or its derivatives have attracted much attention due to the outstanding characteristics of chitosan, such as biocompatibility, hemostatic activity, antibacterial property, and ability to accelerate the wound-healing process [56].

The design of artificial kidney systems has made possible repetitive hemodialysis and the sustaining life of chronic kidney failure patients. Chitosan membranes have been proposed as an artificial kidney membrane because of their suitable permeability and high tensile strength. The most important part of artificial kidney is the semipermeable membrane and so far made from commercial regenerated cellulose and cuprophane. Since the primary action of the cellulose membrane is that of a sieve, there is little selectivity in the separation of two closely related molecules. These novel membranes need to be developed for better control of transport, ease of formability and inherent blood compatibility.

A series of membranes prepared from chitin and its derivatives improved dialysis properties. One of the most serious problems of using these artificial membranes is surface induced thrombosis, where heparization of blood is needed to prevent clotting, and people who are liable to internal hemorrhage can be dialysed only at great risk. Hence, these are the most challenging problem still to be resolved in the development of membranes which are inherently blood compatible. From these point of views, chitosan is hemostatic, i.e., causes clots [57].

Chitosan has replaced the synthetic polymers in opthalmological applications. Chitosan possesses all the characteristics required for an ideal contact lens; optical clarity, mechanical stability, sufficient optical correction, gas permeability, partially towards oxygen, wettability, and immunologically compatibility. Contact lenses are made from partially depolymerized and purified squid pen chitosan by spin casting technology, and these contact lenses are clear, tough, and possess other required physical properties such as modulus, tensile strength, tear strength, elongation, water content, and oxygen permeability. Antimicrobial and wound healing properties of chitosan along with excellent film forming capability make chitosan suitable for development of ocular bandage lens [58]. 
The special attention on chitosan has been paid for the repair of articular cartilage. Articular cartilage is particularly vulnerable to injury trama, disease or congenital abnormalities because of its avascular, alypmhatic and aneural nature. Once damaged, it has little capacity for intrinsic repair. Although many repair techniques have been attempted over the past four decades, but none has succeeded to regenerate long-lasting hyaline cartilage tissue to replace defected or damaged cartilage. Recently, preliminary studies on chitosan-GAG composite and its biologically interaction with articular chondrocytes showed promising results. Chitosan and its derivatives are being extensively used for bone tissue engineering and central nervous system also.

The growth of Escherichia coli was inhibited in the presence of chitosan. Chitosan also inhibited the growth of Fusarium, Alternaria and Helminthosporium. The cationic amino groups of chitosan probably bind to anionic groups of these microorganisms, resulting in growth inhibition. Extracellular lysozyme activity was enhanced in in vitro cultures of several mammalian cells by treatment with chitin and its derivatives. As a result, connective tissue formation was stimulated, and the self-defence function against microbial infection was enhanced at the cellular level. On the basis of these results, several chitin and chitosan dressing materials have been developed commercially for the healing treatment of human and animal wounds [59].

Chitosan is non-toxic and easily bioabsorbable with gel-forming ability at low $\mathrm{pH}$. Moreover, chitosan has antacid and antiulcer activities which prevent or weaken drug irritation in the stomach. Also, chitosan matrix formulations appear to float and gradually swell in an acid medium. All these interesting properties of chitosan make this natural polymer an ideal candidate for controlled drug release formulations [60].

\section{Decellularization}

Autologous grafts are "gold standard" for implantation. However, the most disadvantage of autologous is quantity. The number of autograft does not meet needs of patients. Homograft is greater than autograft but they cannot satisfy needs of patient. Many patients must wait for a long time to take a homogenous organ. Xenograft is the greatest but they can evoke serious immune reaction. So, one method developed to process homograft and xenograft is decellularization. Every tissue/organ concludes cells and extracellular matrix. Cells are structure and functional units of tissue/organ but cells are major antigen of tissue/ organ. Extracellular matrix is many protein, polysaccharide, protoglycan released by cell. ECM plays an important role in mechanical support, signal transportation, adherence of tissue/organ. Decellularization is a multi-step process to remove all cell components from tissue/organ and leave intact ECM. Many decellularization agents were researched such as physical methods, chemical methods and enzyme methods. Every decellularization agent has specific affections of cell and extracellular matrix. So, these agents are combined to make an effective decellularization process which removes all cell components and reverses maximum ECM. Decellularization effectiveness depends on type of tissue/organ. One agent can be a good detergent for decellularizing one tissue but not for another [61]. Moreover, cell derived ECM can be used as a matrix for cell culture. 


\begin{tabular}{|c|c|c|}
\hline Method & Mode of action & Effects on ECM \\
\hline \multicolumn{3}{|l|}{ Physical } \\
\hline Snap freezing & $\begin{array}{l}\text { Intracellular ice crystals disrupt cell } \\
\text { membrane }\end{array}$ & ECM can be disrupted or fracture during rapid freezing \\
\hline Mechanical force & $\begin{array}{l}\text { Pressure can burst cells and tissue removal } \\
\text { eliminates cells }\end{array}$ & Mechanical force can cause damage to ECM \\
\hline Mechanical agitation & $\begin{array}{l}\text { Can cause cell lysis, but more commonly } \\
\text { used to facilitate chemical exposure and } \\
\text { cellular material removal }\end{array}$ & $\begin{array}{l}\text { Aggressive agitation or sonication can disrupt ECM as the } \\
\text { cellular material is removed }\end{array}$ \\
\hline \multicolumn{3}{|l|}{ Chemical } \\
\hline Alkaline; acid & $\begin{array}{l}\text { Solubilize cytoplasmic components of cells; } \\
\text { disrupts nucleic acids }\end{array}$ & Removes GAGs \\
\hline \multicolumn{3}{|l|}{ Non-ionic detergents } \\
\hline Triton $X-100$ & $\begin{array}{l}\text { Disrupts lipid-lipid and lipid-protein } \\
\text { interactions, while leaving protein - } \\
\text { protein interactions intact }\end{array}$ & Mixed results; efficiency dependent on tissue, removes GAGs \\
\hline \multicolumn{3}{|l|}{ Ionic detergents } \\
\hline $\begin{array}{l}\text { Sodium dodecyl sulfate } \\
\text { (SDS) }\end{array}$ & $\begin{array}{l}\text { Solubilize cytoplasmic and nuclear cellular } \\
\text { membranes; tend to denature proteins }\end{array}$ & $\begin{array}{l}\text { Removes nuclear remnants and cytoplasmic proteins; tends } \\
\text { to disrupt native tissue structure, remove GAGs and damage } \\
\text { collagen }\end{array}$ \\
\hline Sodium deoxycholate & & More disruptive to tissue structure than SDS \\
\hline Triton X-200 & & $\begin{array}{l}\text { Yielded efficient cell removal when used with zwitterionic } \\
\text { detergents }\end{array}$ \\
\hline \multicolumn{3}{|l|}{ Zwitterionic detergents } \\
\hline CHAPS & $\begin{array}{l}\text { Exhibit properties of non-ionic and ionic } \\
\text { detergents }\end{array}$ & $\begin{array}{l}\text { Efficient cell removal with ECM disruption similar to that of } \\
\text { Triton } \mathrm{X}-100\end{array}$ \\
\hline Sulfobetaine- 10 and -16 & & Yielded cell removal and mild ECM disruption with Triton \\
\hline (SB-10, SB-16) & & $x-200$ \\
\hline Tri(n-butyl)phosphate & $\begin{array}{l}\text { Organic solvent that disrupts protein- } \\
\text { protein interactions }\end{array}$ & $\begin{array}{l}\text { Variable cell removal; loss of collagen content, although } \\
\text { effect on mechanical properties was minimal }\end{array}$ \\
\hline $\begin{array}{l}\text { Hypotonic and } \\
\text { hypertonic solutions }\end{array}$ & Cell lysis by osmotic shock & $\begin{array}{l}\text { Efficient for cell lysis, but does not effectively remove the } \\
\text { cellular remnants }\end{array}$ \\
\hline EDTA, EGTA & $\begin{array}{l}\text { Chelating agents that bind divalent } \\
\text { metallic ions, thereby disrupting cell } \\
\text { adhesion to ECM }\end{array}$ & $\begin{array}{l}\text { No isolated exposure, typically used with } \\
\text { enzymatic methods (e.g., trypsin) }\end{array}$ \\
\hline \multicolumn{3}{|l|}{ Enzymatic } \\
\hline Trypsin & $\begin{array}{l}\text { Cleaves peptide bonds on the C-side of Arg } \\
\text { and Lys }\end{array}$ & $\begin{array}{l}\text { Prolonged exposure can disrupt ECM structure, removes } \\
\text { laminin, fibronectin, elastin, and GAGs }\end{array}$ \\
\hline Endonucleases & $\begin{array}{l}\text { Catalyze the hydrolysis of the interior } \\
\text { bonds of ribonucleotide and } \\
\text { deoxyribonucleotide chains }\end{array}$ & $\begin{array}{l}\text { Difficult to remove from the tissue and could invoke an } \\
\text { immune response }\end{array}$ \\
\hline Exonucleases & $\begin{array}{l}\text { Catalyze the hydrolysis of the terminal } \\
\text { bonds of ribonucleotide and } \\
\text { deoxyribonucleotide chains }\end{array}$ & \\
\hline
\end{tabular}

Table 1. Overview of decellularization methods (Thomas W. Gilbert) 
Today, many decellularization grafts were applied in clinical treatment such as acellular valve, vascular and some are commercial include: SurgisSIS (porcine small intestinal submicosa), Alloderm (human dermis), ACell (porcine urinary bladder)... Small intestine contains four layers such as mucosa, submucosa, muscularis externa and serosa. Small intestine submucosa (SIS) is a submucosa tissue between mucosa and muscularis externa. SIS is isolated from small intestine by mechanically removing of internal mucosal layer and outer muscular layer. Then, SIS is processed step-by-step with $0.1 \%$ peracid acid, $0.05 \%$ gentamycin and sterilized using $2500 \mathrm{kRad}$ gamma irradiation. SIS is consisted of collagen, proteoglycan, glycosaminoglycan, glycoprotein and growth factor (VEGF, FGF-2 ...). Most of these components can be preserved in extracellular matrix after decellularizing. In tissue engineering, SIS is used as soft tissue grafts such as vascular, skin or used for reconstructing genitourinary, ligament tissue [62].

\subsection{Vascular tissue engineering}

Atherosclerosis is the most dangerous cardiovascular disease. Atherosclerosis is a condition in which vascular wall is harden, thicken because of fatty lipid accumulation. Atherosclerosis is responsible for millions of death all the world every year. In 2004, seventeen million people passed away because of cardiovascular disease all over the world ( $29 \%$ world total death). More than 7 million people are killed by coronary disease $(9.6 \%$ world total death) (WHO). Heart American Association, in 2006, coronary disease was responsible for $17.6 \%$ death in America. One out of six American died for coronary disease [63].

Today, there are some methods to cure atherosclerosis including drug treatment, coronary artery bypass surgery and angioplasty. However, these methods can not cure this condition completely. More than 30\% patients don't have qualified autogenous vascular grafts. Therefore, artificial grafts are made to overcome some current drawbacks.

Artifical graft can be classified into synthetic and biologic scaffold. Synthetic scaffolds include undegradable polymers such as Dacron, ePTFE and degradable polymers such as polylactic acid (PLA) and polyglycolic acid (PGA). Some advantages of synthetic polymers are easy processing, high initial strength, however, they have some disadvantages such as slow recellularization, poor ability to support remodeling. Biologic vascular grafts are either obtained by manipulating native proteins of vascular vessels such as collagen, elastin... or by decellularizing vascular vessels. Decellularized native vascular vessels have some advantages such as slow cost, reduction of graft rejection and immune reaction [64].

In the early time, decellularization studies were tested without cell-seeding. In 1990, Lantz et al use SIS (small intestine submucosa) as small-diameter arterial graft in 18 dogs. 48 weeks after surgery, 28 vascular grafts (75\%) were patent and tree dogs can survive from 76 to 82 weeks after implantation. This result suggested that small intestinal submucosa can be used in small diameter vascular tissue engineering [65]. In 2001, Hodde et al demonstrated that porcine SIS ECM extract containing vascular endothelial growth factor (VEGF) with concentration of 0.77 ng VEGF/g SIS [66]. In the same year, Nemcova et al isolated and decellularized SIS from bovine and porcine. Nine decellularized SIS grafts were implanted into femoral arteries of five male mongrel dogs. After 9 weeks, eight grafts remained patent and some kinds of cell such 
as endothelial cells (ECs), smooth muscle cells (SMCs) invaded into the grafts. No evidence of inflammatory and aneurysmal symptom was observed during the experimental time [67].

However, the main disadvantage of vascular graft is thrombus which ussually occurs immediately in vascular graft lumen after implantation. This process can lead to graft failure and threaten patients' survival. In order to solve this problem, ECs are used as anti-thrombus agent in vascular graft lumen, additionally, SMCs are used to improve mechanical strength of vascular graft. Broschel et al decellularized and recellularized rat iliac arterial grafts. Iliac arterial grafts were decellualrized by glycerin, SDS for 12 hours. Then, decellularized iliac grafts were recellularized with adult rat heart ECs and implanted to femoral arteries of allogeneic rats without systemic anticoagulation injection. After 4 weeks, 2 of 7 control grafts (29\%) were patent (decellularized grafts without recellularization) and 8 of 9 (89\%) experimental grafts (decellularized grafts with recellularization) maintained blood vessel patent [68]. Consequently, this experiment result proved excellent function of ECs in vascular tissue engineering. Some researchers on vascular tissue engineering seeded autologous vascular cells including ECs, SMCs and fibroblasts to make autologous tissue engineered vascular. At the same time, the appearance of bioreactor systems sped up development of vascular tissue engineering. Niklason developed a pulsatile perfusion bioreactor system in 2001. Bioreactor contained a stirbar, a lid for gas exchange and one (or two) silicone tubing(s). Porous vascular scaffolds were threaded over silicone tubing. Bovine aortic SMCs at the passage 2 or 3 were pipetted onto the outer surface of the scaffolds, then bioreactors were slowly rotated and removed to incubator with $10 \% \mathrm{CO}_{2}, 100 \%$ humidity, and $37^{\circ} \mathrm{C}$. Each silicone tubing was linked to a pulsatile perfusion system operated at 165 beats/minute and $260 /-30 \mathrm{mmHg}$. After 8 weeks culture, under nonpulsatile condition, SMC growth was on the outer surface of tubing scaffold and poorly organized. Under pulsatile condition, SMC distribute homogenously in scaffold wall from outer to inner similar to native structure [69].

Nowaday, some decellularized vascular grafts can be obtained from human. Human umbilical veins and arteries can be used in decellularization experiment. Human umbilical arteries were isolated and completely decellularized by Gui et al in 2009. Decellularized umbilical arteries preserved intact collagen matrix and mechanical properties, burst pressure had no signicant change from native form. Decellularized artery graft remained patent after 8 weeks surgery [70]. In 2005, Joel Daniel et al processed human umbilical vein by automated dissection. Human umbilical cord was inserted a mandrel into vein and frozen to -20 and $-80^{\circ} \mathrm{C}$, human umbilical cord was maintained for 12 hours at least at this temperature. The mandrel was lathed with rotation speed of $2900 \mathrm{rpm}$, cutting depth of $750 \mu \mathrm{m}$. Then, human umbilical vein was decellularized with $1 \%(\mathrm{w} / \mathrm{v})$ SDS. The result showed that the treated human umbilical vein contained no cell; burst pressure results were $972.8 \pm 133.8 \mathrm{mmHg}(972 / 1082)$, compliance results were $5.7 \pm 1.3 \%$ over $80-120 \mathrm{mmHg}$. Vascular smooth muscle cells can adhere, proliferate and migrate on the surface of dHUV [71]. Tran Le Bao Ha et al carried out a research on decellularization method for HUVs. HUVs were isolated by manual dissection. HUVs were decellularized by distilled water or $\mathrm{NaCl} 3 \mathrm{M}$ or SDS $1 \%$. The result confirmed that the combination between SDS $1 \%(24 \mathrm{~h})$ and $\mathrm{NaCl} 3 \mathrm{M}(24 \mathrm{~h})$ showed the best effective on cellular elimination. 

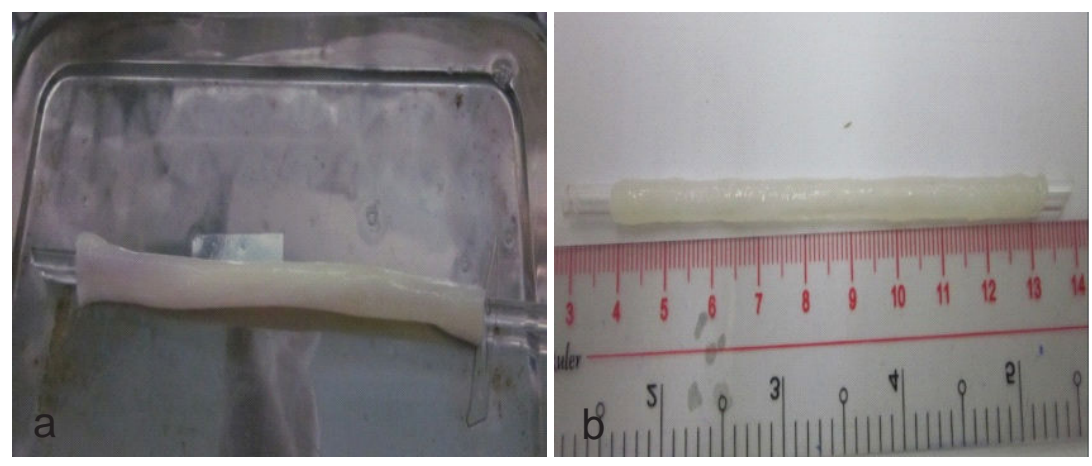

Figure 6. Human umbilical cord (a) and human umbilical vien (b)
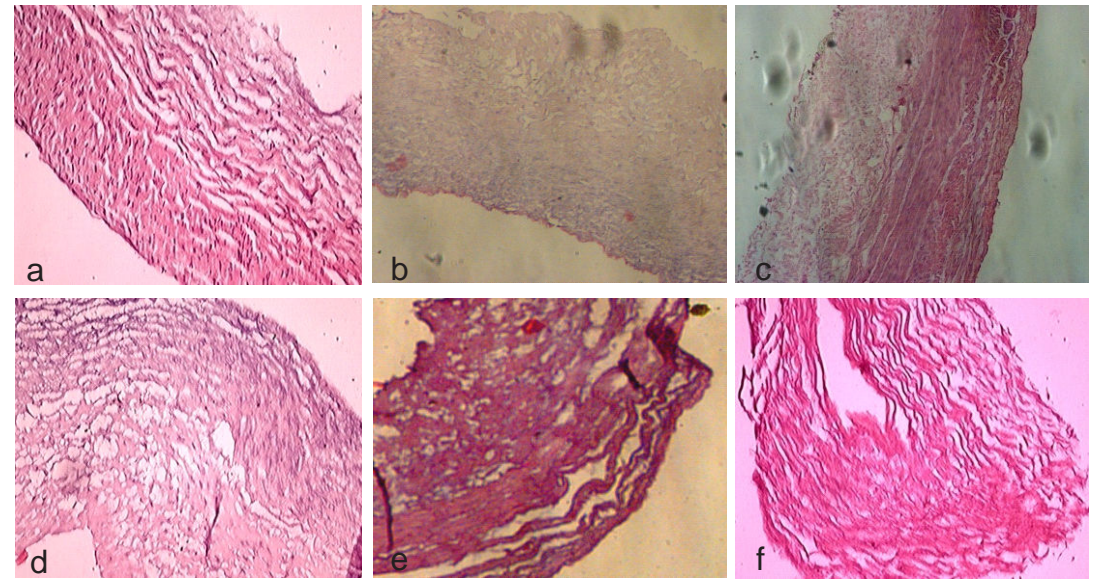

Figure 7. HE staining of HUV with different decellularization methods. Control (a), distilled water (b), $\mathrm{NaCl} 3 \mathrm{M}$ (c), SDS $1 \% 24 \mathrm{~h}(\mathrm{~d})$, SDS $1 \% 36 \mathrm{~h}(\mathrm{e}), \mathrm{SDS} 1 \% 24$. and $\mathrm{NaCl} 3 \mathrm{M} 24 \mathrm{~h}(\mathrm{f})$

\subsection{ECM from cultured cells}

One of the most important properties of ECM is its functional diversity. ECM has been reported to support and enhance for adhesion, migration, proliferation of cells as well as to create stem cell niches in vitro.. ECM can be harvested from different sources, one of which is from cells under culture condition. When cultured, cells will produce three-dimensional matrix surrounding themselves. A method is described for generating tissue culture surfaces coated with a human fibroblast-derived ECM [72, 73, 74, 75].

For this purpose, human foreskin fibroblasts are isolated, plated and cultured until third passage (see Figure 8). Fibroblasts are maintained in culture medium until reaching 80\% 
confluency and stimulated to synthesize ECM by culture medium supplemented ascorbic acid. Matrices are denuded of cells and cellular remnants are removed by using Triton X-100, $\mathrm{NH}_{4} \mathrm{OH}$ and DNase.

Then, ECM coated culture surfaces are tested by staining with PI to access DNA remnant (see Figure 9), with H\&E and PAS in order to characterize component of ECM. The results suggest that fibroblast-derived three-dimensional matrix was determined to be free of cellular constituents and still remain attached to the culture surface. The conducted matrices were washed and covered with PBS; and stored at $4^{\circ} \mathrm{C}$. Under these conditions, biological activity (for example, induction of cell attachment, proliferation...) was reported to be well-preserved for up to 6 months.

In order to evaluate the quality of the ECM, the test of cell rapid attachment ability is performed. Cell proliferation on ECM is also assessed. Results showed that the cultured cells attached and proliferated on ECM coated surfaces faster than on ECM non-coated surfaces.
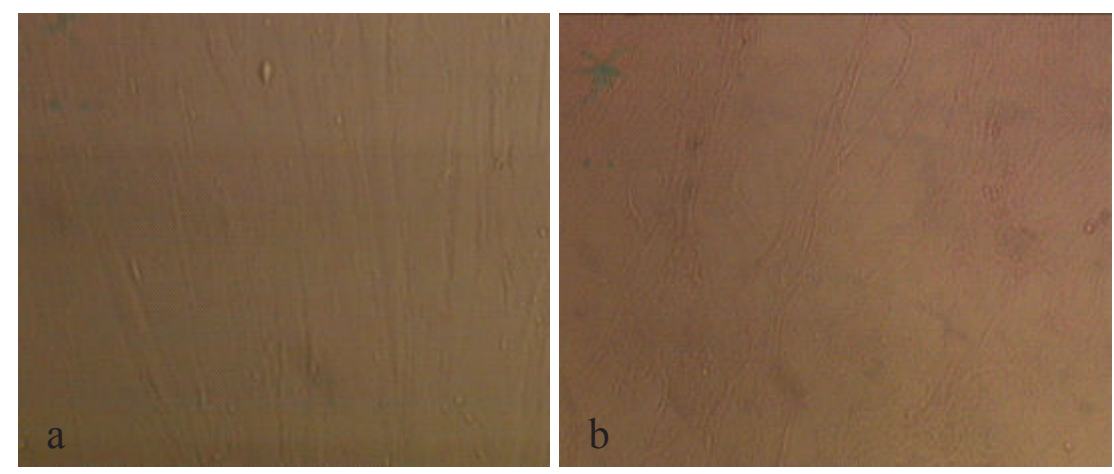

Figure 8. Fibroblasts are in cultured surfaces (a) and are stimulated to synthesize ECM (b)
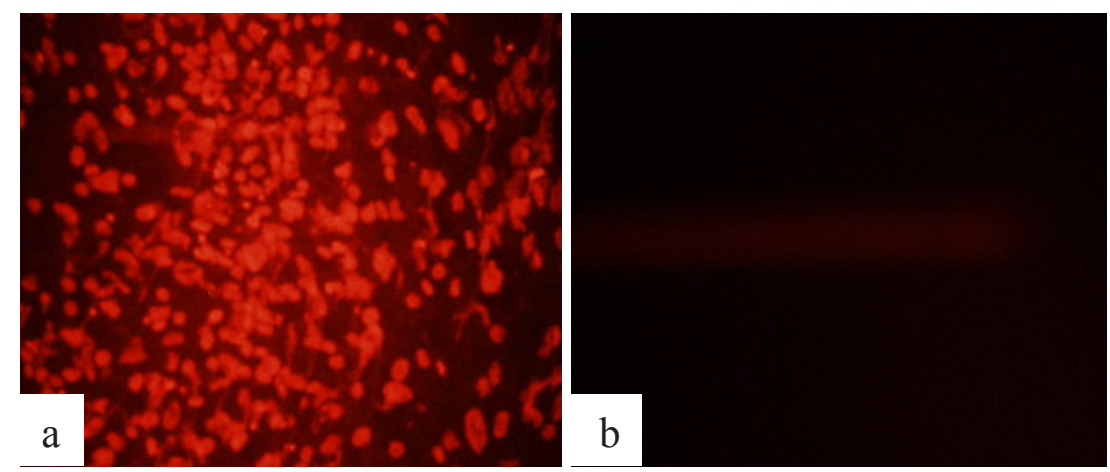

Figure 9. ECM stained PI before (a) and after (b) using DNase 

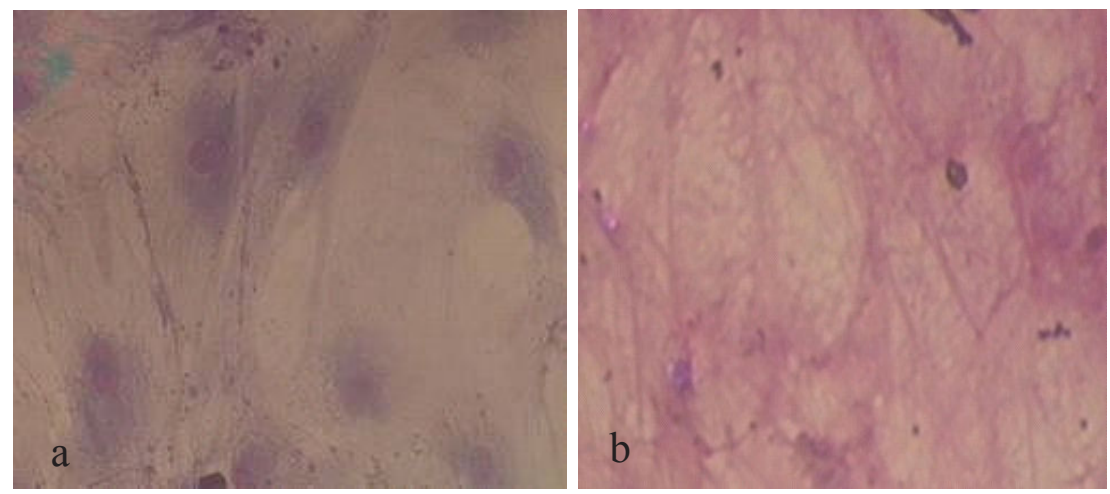

Figure 10. Culture surface before (a) and after (b) is denuded cells

\section{Conclusion}

In modern society, many diseases have been increasing in human because of pollution, accident, lifestyle... The mutilation in human body leads to expand the needs of replacing tissues/ organs. However, the available source of tissues/organs is limited. Creating artificial tissues/ organs for replacing damaged, dysfunctional tissues/organs becomesabig discipline on material science. Naturally derived biomaterials have been studied and applied in clinical applications as artificial tissues/organs because they are capable of supporting cell proliferation, biodegradability and remodeling tissues. Although the current results have not completely satisfy the clinical demand, the potential applications of naturally derived biomaterials are still highly considered, therefore, research on this field have now being taken place all over the world.

\section{Author details}

Tran Le Bao Ha*, To Minh Quan, Doan Nguyen Vu and Do Minh Si

*Address all correspondence to: tlbha@hcmus.edu.vn

University of Science, Vietnam National University - Hochiminh city, Vietnam

\section{References}

[1] Lodish, H, Berk, A, \& Zipursky, S. L. Molecular Cell Biology. New York: W. H. Freeman (2000). 
[2] Anu, M. Type XV collagen. University of Oulu (2001).

[3] Hassan, N, Habibollah, P, \& Abolhassan, A. Properties of the amniotic membrane for potential use in tissue engineering. European cells \& materials (2008). , 15, 88-89.

[4] Andrew, H, Vijay, A. S, Trevor, G, Aaron, M. Y, James, L, David, K. J, \& Harminder, S. D. Optimization of amniotic membrane (AM) denuding for tissue engineering. Tissue engineering (2008). , 14, 371-383.

[5] Singh, R, Purohit, S, \& Chacharkar, M. P. Effect of high doses of gamma radiation on the functional characteristics of amniotic membrane. Radiation Physics and Chemistry (2007). , 76, 1026-1030.

[6] Loss, M, Wedler, V, Kunzi, W, Meuli-simmen, C, \& Meyer, V. E. Artificial skin, splitthickness autograft and cultured autologous keratinocytes combined to treat a severe burn injury of $93 \%$ of TBSA. Burns (2000). , 26, 644-652.

[7] Ludwik, K. B, David, N. H, Mario, M. C, William, B. N, Oscar, E. M, \& Marc, G. J. Amnion in the treatment of pediatric partial-thickness facial burns. Burns (2008). , 34, 393-399.

[8] Susan, S. Y. Current Protocols in Cell Biology. John Wiley \& Sons, Inc. (2003). , 1-2.

[9] Rose, P. J, Mark, H. F, Bikales, N. M, Overberger, C. G, Menges, G, \& Kroschwitz, J. I. editors. Encyclopedia of polymer science and engineering. New York, USA: Wiley (1989). , 488-513.

[10] Draget, K. I, Smidsrod, O, \& Skjàk-bræk, G. Alginate from algae. In Polysaccharide and Polyamides in the food Industry. In: Steinbüchel A, Rhee SK. (eds). Wiley-VCH Verlag GmbH \& Co.: Weinheim (2005). , 1-30.

[11] Ertesvåg, H, Valla, S, \& Skjåk-bræk, G. Genetics and biosynthesis of alginates. Carbohyd. Europe (1996). , 14, 14-18.

[12] Paul, W, \& Sharma, C. P. Chitosan and Alginate Wound Dressings: A Short Review. Trends in Biomaterials and Artificial Organs (2004). , 18, 18-23.

[13] Chen, J. P, Chu, I. M, Shiao, M. Y, Hsu, B. R, \& Fu, S. H. Microencapsulation of islets in PEG amine modified alginate-poly(l-lysine)-alginate microcapsules for constructing bioartificial pancreas. Journal of Fermentation and Bioengineering (1998). , 86, 185-190.

[14] Rowley, J. A, Madlambayan, G, \& Mooney, D. J. Alginate hydrogels as synthetic extracellular matrix materials. Biomaterials (1999). , 20, 45-53.

[15] Seifert, D. B, \& Phillips, J. A. Porous alginate-poly(ethylene glycol) entrapment system for the cultivation of mammalian cells. Biotechnology progress (1997). , 13, 569-576.

[16] Altman, G. H. Silk-based biomaterials. Biomaterials (2003). , 24, 401-416. 
[17] Tanaka, K, Inoue, S, \& Mizuno, S. Hydrophobic interaction of containing Asn-linked oligosaccharide chains, with the H-L complex of silk fibroin produced by B. mori. Insect Biochemistry and Molecular Biology (1999). , 25.

[18] Inoue, S. Silk fibroin of Bombyx mori is secreted, assembling a high molecular mass elementary unit consisting of H-chain, L-chain, and with a 6:6:1 molar ratio. Journal of Biological Chemistry (2000). , 25.

[19] Seidel, A. Regenerated spider silk: Processing, properties, and structure. Macromolecules (2000). , 33, 775-780.

[20] Xu, M. Structure of a protein superfiber: spider dragline silk. Proceedings of the National Academy of Sciences of the United States of America (1990). , 87, 7120-7124.

[21] Kumaresan, P. Sericin a versatile by product. Indian Silk (2007). , 45, 11-13.

[22] Dandin, S. B. Biomedical uses of silk and its derivatives. Indian Silk (2007). , 45, 5-8.

[23] Gulrajani, M. L. Sericin-a bio-molecule of value. Indian Silk (2006). , 45, 16-22.

[24] Wang, Y. Cartilage tissue engineering with silk scaffolds and human articular chondrocytes. Biomaterials (2006). , 27, 4434-4442.

[25] Sofia, S. Functionalized silk-based biomaterials for bone formation. Journal of Biomedical Materials Research (2001). , 54, 139-148.

[26] Megeed, Z. Genetically engineered silk-elastinlike protein polymers for controlled drug delivery. Advanced drug delivery reviews (2002). , 54, 1075-1091.

[27] Medved, L. V, Gorkun, O. V, \& Privalov, P. L. Structural organiza-tion of C-terminal parts of fibrinogen A alpha-chains. FEBS Lett (1983). , 160, 291-295.

[28] Ferry, J. D, \& Morrison, P. R. Preparation and properties of serum and plasma proteins. VIII. The conversion of human fibrinogen to fibrin under various conditions. Journal of the American Chemical Society (1947). , 69, 388-400.

[29] Betts, L, Merenbloom, B. K, \& Lord, S. T. The structure of fibrinogen fragment D with the 'A' knob peptide GPRVVE. Journal of Thrombosis and Haemostasis (2006). , 4, $1139-1141$.

[30] Ryan, E. A, Mockros, L. F, Stern, A. M, \& Lorand, L. Influence of a natural and a synthetic inhibitor of factor XIIIa on fibrin clot rheology. Biophysical Journal (1999). , 77, 2827-2836.

[31] Collet, J. P, Shuman, H, Ledger, R. E, Lee, S, \& Weisel, J. W. The elasticity of an individual fibrin fiber in a clot. Proceedings of the National Academy of Sciences of the United States of America (2005). , 102, 9133-9137.

[32] Kaitlin, C, \& Murphy, J. Kent Leach. A reproducible, high throughput method for fabricating fibrin gels. BMC Research Notes (2012). 
[33] Bensaïd, W, Triffitt, J. T, Blanchat, C, Oudina, K, Sedel, L, \& Petite, H. A biodegradable fibrin scaffold for mesenchymal stem cell transplantation. Biomaterials (2003). , 24, 2497-2502.

[34] Okada, M, \& Blomback, B. Calcium and fibrin gel structure. Thrombosis Research (1983). , 29, 269-280.

[35] Siebenlist, K. R, \& Mosesson, M. W. Progressive cross-linking of fibrin gamma chains increases resistance to fibrinolysis. Journal of Biological Chemistry (1994). , 269, 28414-28419.

[36] Alan, R. H, Dennis, K. G, Mark, P. H, Frank, C. S, \& Constantine, E. Autologous Whole Plasma Fibrin Gel: Intraoperative Procurement. Archieves of Surgery (1992). , 127, 357-359.

[37] Ye, Q, Zünd, G, \& Benedikt, P. Fibrin gel as a three dimensional matrix in cardiovascular tissue engineering. European Journal of Cardio-thoracic Surgery (2000). , 17, 587-591.

[38] Bensa, W, Triffittb, J. T, Blanchata, C, Oudinaa, K, Sedela, L, \& Petitea, H. A biodegradable fibrin scaffold for mesenchymal stemcell transplantation. Biomaterials (2003). , 2497-2502.

[39] Saltz, R, Dimick, A, Harris, C, Grotting, J. C, Psillakis, J, \& Vasconez, L. O. Application of autologous fibrin glue in burn wounds. Journal of Burn Care \& Rehabilitation (1989). , 10, 504-507.

[40] Klemm, D, Philipp, B, Heinze, T, Heinze, U, \& Wagenknecht, W. Comprehensive Cellulose Chemistry. Fundamentals and Analytical Methods. Wiley-VCH, Weinheim (1998).

[41] Myasoedova, V. V. Physical chemistry of non-aqueous solutions of cellulose and its derivatives. John Wiley and Sons, Chirchester (2000).

[42] Robert, J. M, Ashlie, M, John, N, John, S, \& Je, Y. Cellulose nanomaterials review: structure, properties and nanocomposites. Chemical Society Reviews (2011). , 40, 3941-3994.

[43] Nabar, G. M, \& Padmanabhan, C V. Studies in oxycellulose. Proceedings of the Indian Academy of Sciences (1950). , 31, 371-380.

[44] Kibbe, A. H. Handbook of pharmaceutical excipients: Cellulose, silicified microcrystalline. American Public Health Association. Washington (2000).

[45] Wadworth, L. C, \& Daponte, D. Cellulose esters. In: Nevell TP, Zeronian SH (ed.) Cellulose Chemistry and its Applications. Ellis Horwood, Chich-ester (1985). , 349-362.

[46] Delgado, J. N, \& William, A. Wilson and Gisvold's textbook of organic medicinal and pharmaceutical chemistry. Lippincott-Raven Publishers, Wickford (1998). 
[47] Svensson, A, Nicklasson, E, Harrah, T, Panilaitis, B, Kaplan, D, Brittberg, M, \& Gatenholm, P. Bacterial Cellulose as a Potential Scaffold for Tissue Engineering of Cartilage. Biomaterials (2005). , 26, 419-431.

[48] Muzzarellieditor. Natural Chelating Polymers. Pergamon Press, New York (1973).

[49] Zikakiseditor. Chitin, Chitosan and Related Enzymes. Academic Press, Orlando (1984).

[50] Dutta, P. K. Ravikumar MNV, Dutta J. Chitin and chitosan for versatile applications, Journal of Macromolecular Science-polymer Reviews (2002). , 42, 307-315.

[51] Kurita, K. Chemistry and application of chitin and chitosan, Polymer Degradation and Stability (1998). , 59, 117-120.

[52] Sashiwa, H, Shigemasa, Y, \& Roy, R. Chemical modification of chitosan: synthesis of dendronized chitosan-sialic acid hybrid using convergent grafting of preassembled dendrons built on gallic acid and tri(ethylene glycol) backbone. Macromolocules (2001). , 34, 3905-3920.

[53] Baba, Y, Noma, H, Nakayama, R, \& Matsushita, Y. Preparation of chitosan derivatives containing methylthiocarbamoyl and phenylthiocarbamoyl groups and their selective adsorption of copper (II) over iron (III). Analytical sciences (2002). , 18, 359-370.

[54] Qu, X, Wirsen, A, \& Albertsson, A. C. Effect of lactic/glycolic acid side chains on the thermal degradation kinetics of chitosan derivatives. Polymer (2001). , 41, 4841-4850.

[55] Madhavan editor. Chitin Chitosan and their Novel Applications. Science Lecture Series, CIFT, Kochi (1992).

[56] Prasitslip, M, Jenwithisuk, R, Kongsuwan, K, Damrongchai, N, \& Watts, P. Cellular responses to chitosan in vitro: the importance of deacetylation, Journal of Materials Science: Materials in Medicine (2000). , 11, 773-780.

[57] Lin, W. C, Liu, T. Y, \& Yang, M. C. Hemocompatibility of polyacrylonitrile dialysis membrane immobilized with chitosan and heparin conjugate. Biomaterials (2003).

[58] Markey Bowman, Bergamini, editor. Chitin and Chitosan. Elsevier Applied Science, London (1989).

[59] Gebelein CarraherJr, editor. Industrial Biotechnological Polymers. Technomic, Lancaster (1995).

[60] Uhrich, K. E, Cannizzaro, S. M, Langer, R. L, \& Shakesheff, K. M. Polymeric systems for controlled drug release. Chemical Reviews (1999). , 99, 3181-3190.

[61] Thomas, W. G. Decellularization of tissues and organs, Biomaterials (2006). , 27, 3675-3683. 
[62] Jason, H. Naturally Occurring Scaffold for Soft Tissue Repair and Regeneration. Tissue Engineering (2002). , 8, 295-308.

[63] Véronique, L. R. Heart Disease and Stroke Statistics- (2012). Update: A Report from the Amercian Heart Association. Circulation 2012.

[64] Chrysanthi, W. Engineering of Small Diamter Vessels.Therapeutic applications: tissue therapy; , 1000-1013.

[65] Lantz Small Intestinal Submucosa as a Small-Diameter Arterial Graft in the Dog. Journal of Investigative Surgery (1990). , 3, 217-227.

[66] Hodde, J. P. Vascular endothelial growth factor in porcine-derived extracellular matrix. Endothelium (2001). , 8, 11-24.

[67] Nemcova, S, Noel, A. A, Jost, C. J, Gloviczki, P, Miller, V. M, \& Brockbank, K. G. Evaluation of a xenogeneic acellular collagen matrix as a small-diameter vascular graft in dogs preliminary observations. Journal of Investigative Surgery (2001).

[68] Borschel, G. H. Tissue engineering of recellularized small-diameter vascular grafts. Tissue Engineering (2005). , 11, 778-786.

[69] Laura, E. N. Morphologic and mechanical characteristics of engineered bovine arteries. Journal of vascular surgery (2001). , 33, 628-638.

[70] Gui, L. Development of decellularized human umbilical arteries as small-diameter vascular grafts. Tissue Engineering (2009). , 15, 2665-2676.

[71] Joel, D. Development of the Human Umbilical Vein Scaffold for Cardiovascular Tissue Engineering Applications. ASAIO Journal (2005). , 51, 252-261.

[72] Kenneth, M. Y. Current Protocols in Cell Biology. John Wiley \& Sons, Inc. (2003). , $1-10$.

[73] Badylak, S, Gilbert, T, \& Irvin, J. The extracellular matrix as a biologic scaffold for tissue engineering. Tissue Engineering (2008). , 121-144.

[74] Chen, R. N, Ho, H. O, Tsai, Y. T, \& Sheu, M. T. Process development of an acellular dermal matrix (ADM) for biomedical application. Biomaterials (2004). , 25, 2679-2686.

[75] Cheng, Z. J, So, R. P, Byung, H. C, Kwideok, P, \& Byoung, H. M. In vivo cartilage tissue engineering using a cell-derived extracellular matrix scaffold. Artificial Organs (2007). , 31, 183-192. 